\title{
Palliative pulmonary artery banding versus anatomic correction for congenitally corrected transposition of the great arteries with regressed morphologic left ventricle: Long-term results from a single center
}

Kai Ma, MD, PhD, Huawei Gao, MD, PhD, Zhongdong Hua, MD, Keming Yang, MD, Shengshou $\mathrm{Hu}, \mathrm{MD}, \mathrm{PhD}$, Hao Zhang, MD, PhD, and Shoujun Li, MD

\begin{abstract}
Objective: We aimed to compare the long-term results between palliative pulmonary artery banding and anatomic correction for congenitally corrected transposition of the great arteries with regressed morphologic left ventricle.
\end{abstract}

\begin{abstract}
Methods: From 2003 to 2012, 40 consecutive patients underwent first-stage pulmonary artery banding. The second-stage operation-double switch-was performed in 15 patients (double-switch group). The other 25 patients retained pulmonary artery banding without further operation (pulmonary artery banding group). Inhospital mortality, long-term mortality, and heart function were studied as primary outcomes.

Results: The median time of follow-up was $3.4 \pm 0.7$ years (range, 6 months-9.5 years). Overall survival rate was $66.7 \%$ in the double-switch group versus $96.0 \%$ in the pulmonary artery banding group $(P=.03)$. The ratio of New York Heart Association functional class I-II $(80.0 \%$ vs $95.9 \% ; P=.02)$ and the mean functional left ventricle ejection fraction $(51.4 \% \pm 9.6 \%$ vs $61.0 \% \pm 6.4 \% ; P=.01)$ were higher in the pulmonary artery banding group at follow-up. In univariate analysis, age at pulmonary artery banding was the only risk factor for late deaths (odds ratio, 7.30; $P=.01$ ) and left ventricle dysfunction (odds ratio, $4.77 ; P=.03$ ) after the double switch. For patients who experienced prolonged pulmonary artery banding, mean oxygen saturation was $95 \% \pm 3.1 \%$ and the trans-banding pressure gradient was $46.9 \pm 21.5 \mathrm{~mm} \mathrm{Hg}$.
\end{abstract}

Conclusions: In patients with congenitally corrected transposition of the great arteries with deconditioned morphologic left ventricle pulmonary artery banding may be considered an ideal procedure because it allows left ventricle training while improving tricuspid regurgitation. Compared with the double-switch procedure after pulmonary artery banding, prolonged palliative pulmonary artery banding provided a lower mortality rate and indicated better cardiac function. (J Thorac Cardiovasc Surg 2014;148:1566-71)

Congenitally corrected transposition of the great arteries (ccTGA) is characterized by the combination of atrioventricular and ventriculoarterial discordance. The morphologic left ventricle $(\mathrm{mLV})$ and morphologic right ventricle (mRV) support the pulmonary and systemic circulations, respectively. The $\mathrm{mRV}$ is not ideally suited for the long-

From the Pediatric Cardiac Surgery Center, State Key Laboratory of Cardiovascular Disease, National Center for Cardiovascular Disease; and Fuwai Hospital, Chinese Academy of Medical Sciences, Peking Union Medical College, Beijing, China.

Supported by the Program for Peking Union Medical College Scholars and Innovative Research Team (grant No. 2011-XH5\#).

Disclosures: Authors have nothing to disclose with regard to commercial support.

Read at the European Society of Cardiology Congress 2013, Amsterdam, The Netherlands, August 31-September 4, 2013.

Received for publication July 10, 2013; revisions received Nov 27, 2013; accepted for publication Dec 24, 2013; available ahead of print Feb 14, 2014.

Address for reprints: Shoujun Li, MD, Department of Cardiac Surgery, Fuwai Hospital, Chinese Academy of Medical Sciences, Peking Union Medical College, 167 Beilishi Rd, Xicheng District, Beijing, 100037, China (E-mail: drlishoujun@ yahoo.com)

$0022-5223 / \$ 36.00$

Copyright (c) 2014 by The American Association for Thoracic Surgery

http://dx.doi.org/10.1016/j.jtcvs.2013.12.044 term maintenance of the systemic circulation. In time it may fail under these conditions because of its anatomic and physiologic substrate. The major manifestation of $\mathrm{mRV}$ dysfunction is tricuspid regurgitation (TR), which is associated with increased morbidity and mortality in patients with ccTGA.

Surgical approaches for ccTGA include conventional and anatomic repair. It has become apparent that the long-term outcomes of conventional repair, whereby the right ventricle remains in the systemic circulation, are not satisfactory. ${ }^{1-5}$ As such, the lesion itself is far from corrected. True correction, in terms of restoring the $\mathrm{mLV}$ to the systemic circulation, has been achieved by double-switch (DS) operation.

The success of DS procedures depends on the ability of the left ventricle to support systemic circulation. In the absence of unrestrictive ventricular septal defect and pulmonary arterial hypertension, the $\mathrm{mLV}$ will be deconditioned and cannot undertake the workload of systemic circulation. Pulmonary artery banding (PAB) is considered to be the ideal method for training $\mathrm{mLV}$ function. If the 


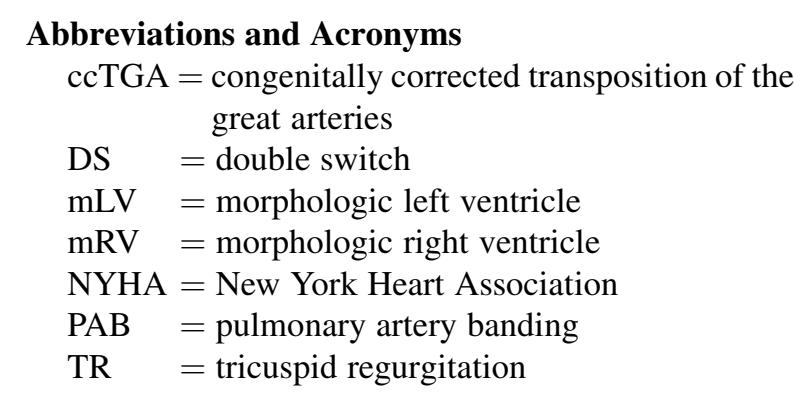

function of the $\mathrm{mLV}$ is strong enough to be the main blood pump after PAB, the DS procedure will be done safely. This 2-stage strategy is now considered the optimal choice for patients with a deconditioned $\mathrm{mLV}$. However, deterioration in left ventricle function in trained groups of patients has been reported, and there is concern that this will be a significant long-term problem. ${ }^{6}$ Is it better to enroll patients who have a regressed $\mathrm{mLV}$ in a program of retraining of the left ventricle followed by a DS procedure than to perform palliative $\mathrm{PAB}$ alone? We followed all patients who underwent PAB (with or without the second-stage DS) to compare the outcomes between DS and PAB as the long-term palliative procedure.

\section{MATERIALS AND METHODS \\ Patients}

Forty consecutive patients underwent $\mathrm{PAB}$ with or without the secondstage DS at Fuwai Hospital from January 2003 through December 2012. All patients were diagnosed with ccTGA without left ventricular outflow tract obstruction. The second-stage DS was performed in 15 patients (DS group) and palliative $\mathrm{PAB}$ was regarded as the ending procedure in the other 25 patients (PAB group). This study was approved by the Ethics Committee at Fuwai Hospital. They gave us their approval to waive the need for patient consent for publishing follow-up data about these patients. Followup information was completed in all patients. The median time of follow-up was $3.4 \pm 0.7$ years (range, 6 months-9.5 years).

\section{Clinical Protocols and Surgical Techniques}

All patients had objective evidence of TR and $\mathrm{mRV}$ dilation. PAB was used as an interim measure to both train the $\mathrm{mLV}$ for future DS and relieve the TR. The target mLV:mRV pressure ratio after PAB was 0.50-0.75 irrespective of the patient's age, underlying diagnosis, or baseline left ventricular pressure. The DS procedure was performed only when the mLV was considered to be well conditioned. Assessment for suitability for DS procedure was by means of transthoracic echocardiography and/or cardiac catheterization. Criteria for second-stage DS included $\mathrm{mLV}$ pressures $>75 \%$ of systemic pressure for at least several months, less than moderate ventricular dysfunction, and less than moderate mitral regurgitation. The mLV mass index and mass:volume ratios were not calculated and not used in decision making.

\section{PAB}

Access was obtained via median sternotomy. The $\mathrm{mLV}$ and $\mathrm{mRV}$ pressures were measured by direct manometry before $\mathrm{PAB}$. The $\mathrm{PAB}$ procedure was performed on the pulmonary trunk away from the pulmonary valve with the use of a polytetrafluoroethylene band (Gore-Tex, W. L. Gore \&
Associates, Inc, Flagstaff, Ariz). The aim of banding was to achieve an intraoperative $\mathrm{mLV}$ pressure $0.50-0.75$ of the systemic pressure.

\section{DS}

The DS approach was made through the previous incision for PAB. Ventricular septal defect repair was performed transatrially, through the aorta or through the right ventricle. The Senning procedure was used for atrial switch in all DS patients. The Lecompte maneuver was generally performed if the great arteries were not located side by side. Sinotubular junction plasty of the neoaorta was performed to repress root dilation. Tricuspid valvuloplasty was performed simultaneously in 3 patients.

\section{Data Collection}

Patient demographics and clinical data were obtained from our local database. Ventricle function and size were assessed by echocardiography. A single cardiologist reviewed all previous echocardiograms and performed independent measurements. In-hospital mortality was defined as both 30-day mortality and death any time after operation but before discharge. Follow-up mortality was defined as death after 30 days or after discharge if length of hospital stay was $>30$ days. Reoperation included only reoperations on the heart and excluded secondary closure of the sternum and revision for bleeding or mediastinitis. Valvular regurgitation was considered substantial when documented as moderate or severe. $\mathrm{mLV}$ dysfunction was defined as mLV ejection fraction $<60 \%$.

\section{Statistical Analysis}

Results are presented as mean \pm standard deviation for continuous variables with normal distribution, as median and range for variables with nonnormal distribution, and as frequency and percent for categorical variables. Time to death and neoaortic regurgitation at follow-up are displayed by Kaplan-Meier curves. Comparisons of variables were made using the Student $t$ test, the $\chi^{2}$ test, or the Fisher exact test, as appropriate. Multivariate analysis could not be performed because the ratio of events per variable was too small. The level of significance was set at $\alpha=0.05$. Analysis was conducted using SPSS version 17.0 (IBM-SPSS Inc, Armonk, NY) for Windows.

\section{RESULTS \\ Patient Population and Anatomic Characteristics}

The study group consisted of 23 men and 17 women. The median age at PAB of these patients was 3.1 years (range, 2 months-10 years), and their median weight at banding was $11.5 \mathrm{~kg}$ (range, 5.1-22.0 kg). In this cohort, 28 patients $(70.0 \%)$ had a patent ductus arteriosus $(\leq 3 \mathrm{~mm}$ on echocardiogram), 22 patients $(55.0 \%$ ) had an additional restrictive ventricular septal defect with no hemodynamic significance. TR was present in all patients, including 7 mild, 14 moderate, and 19 severe. One patient had dextrocardia. There were no pre-PAB procedures. The baseline data for these 2 groups are shown in Table 1 .

\section{Early Outcomes After PAB}

There was no death in either group after PAB. The pressure gradient trans-banding was $53.2 \pm 11.1 \mathrm{~mm} \mathrm{Hg}$, although the $\mathrm{mLV}: \mathrm{mRV}$ pressure ratio increased from $0.31 \pm 0.15$ to $0.63 \pm 0.16$ immediately after banding $(0.63 \pm 0.14$ in PAB group vs $0.65 \pm 0.17$ in DS group; $P=.89$ ). No patient required removal of the band for 
TABLE 1. Patient characteristics in the 2 groups

\begin{tabular}{|c|c|c|c|}
\hline Patient characteristic & DS group $(n=15)$ & PAB group $(n=25)$ & $P$ value \\
\hline Age at PAB & 3.0 y (3 mo-10 y) & 2.0 y $(2 \mathrm{mo}-8 \mathrm{y})$ & .392 \\
\hline Weight at PAB (kg) & $13.0(5.2-19.3)$ & $11.4(5.1-22.0)$ & .598 \\
\hline Male gender & $8(61.5)$ & $15(75.0)$ & .461 \\
\hline PDA & $11(84.6)$ & $17(85.0)$ & 1.000 \\
\hline VSD without hemodynamic significance & $9(69.2)$ & $13(65.0)$ & 1.000 \\
\hline Tricuspid regurgitation & & & .513 \\
\hline Mild & $3(20.0)$ & $4(16.0)$ & \\
\hline Moderate & $5(33.3)$ & $9(36.0)$ & \\
\hline Severe & $7(46.6)$ & $12(48.0)$ & \\
\hline $\mathrm{mLV}: \mathrm{mRV}$ systolic pressure ratio before training & $0.31 \pm 0.09$ & $0.32 \pm 0.08$ & .837 \\
\hline
\end{tabular}

Data are presented as median (range), $\mathrm{n}(\%)$, or median \pm standard error. $D S$, Double switch; $P A B$, pulmonary artery banding; $P D A$, patent ductus arteriosus; $V S D$, ventricular septal defect; $m L V$, morphologic left ventricle; $m R V$, morphologic right ventricle.

PAB. One patient required tightening of the band (rebanding) early after the initial procedure. Another 2 patients required late rebanding. The interval between initial PA banding and rebanding was 10 days, 6.9 months, and 13.7 months, respectively. No early left ventricle systolic/diastolic dysfunction was noted. No patients requiring early rebanding underwent late rebanding. Fifteen patients underwent DS. The duration of training for patients in the DS group who achieved anatomic repair was 17.2 months (range, 1 week-36.1 months). The mean mLV:mRV pressure ratio before DS was $0.80 \pm 0.04$. The reason for absence of DS was mLV less response in 15 patients (ie, far from well-prepared $\mathrm{mLV}$ was noted by echocardiography evaluation; mLV:mRV pressure ratio at latest followup was not available because these 15 patients did not undergo cardiac catheterization), prolonged family preparation in 6 patients, and concomitant illness in 4 patients. Early after banding, mRV ejection fraction improved from $50.8 \% \pm 11.7 \%$ to $63.3 \% \pm 8.1 \%(P=.04)$. Improvement in TR can be viewed in Figure 1.

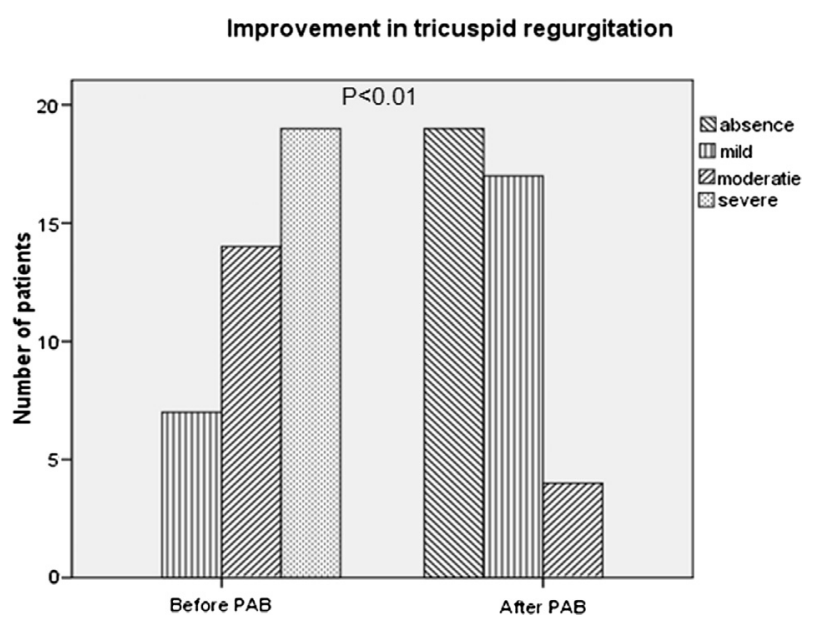

FIGURE 1. Improvement in tricuspid regurgitation. $P A B$, Pulmonary artery banding.

\section{Perioperative Outcomes of DS}

In the DS group, there was no early death after DS procedure. No reoperation, reintervention, extracorporeal membrane oxygenation, or permanent pacing were required during the early postoperative period. All patients were in New York Heart Association (NYHA) functional class I-II and no mLV dysfunction was detected at discharge. More information on perioperative outcomes of DS procedure is available in Table 2.

\section{Follow-up Outcomes}

At follow-up there were 5 deaths in the DS group. Three were because of $\mathrm{mLV}$ failure. The other 2 died of sudden death and pulmonary infection, respectively. In univariate analysis, age at PAB was a risk factor for late death (odds ratio $[\mathrm{OR}], 7.30 ; P=.01)$ and left ventricle dysfunction after DS procedure $(\mathrm{OR}, 4.77 ; P=.03)$, whereas pre-DS $\mathrm{mLV}: \mathrm{mRV}$ pressure ratio was not $(\mathrm{OR}, 2.40 ; P=.56$ for late deaths and OR, 5.05; $P=.22$ for left ventricle dysfunction). The pre-DS mLV:mRV pressure ratio of the 3 patients who experienced late death caused by $\mathrm{mLV}$ dysfunction was $0.78,076$, and 0.77 , respectively. There was no difference in pre-DS mLV:mRV pressure ratio found among these 3 patients who died and other patients $(0.77 \pm 0.01$ vs 0.82

TABLE 2. Perioperative variables of double-switch (DS) procedure

\begin{tabular}{lc}
\hline \multicolumn{1}{c}{ Variable } & DS group $(\mathbf{n}=\mathbf{1 5})$ \\
\hline Inotropes/ventilation before DS & 0 \\
CPB time (min) & $163 \pm 41$ \\
Aortic crossclamp time (min) & $104 \pm 37$ \\
Delayed sternal closure & $3(20)$ \\
LA pressure at ICU arrival (mm Hg) & $8.1 \pm 0.8$ \\
Ventilation time (h) & $53.3 \pm 39.0$ \\
ICU stay time (d) & $4.4 \pm 3.1$ \\
Postoperative length of stay (d) & $19.9 \pm 10.9$ \\
Peritoneal dialysis & 0 \\
\hline Data are presented as n (\%) or mean \pm standard deviation. $C P B$, Cardiopulmonary \\
bypass; $L A$, left atria; $I C U$, intensive care unit; $D S$, double switch.
\end{tabular}




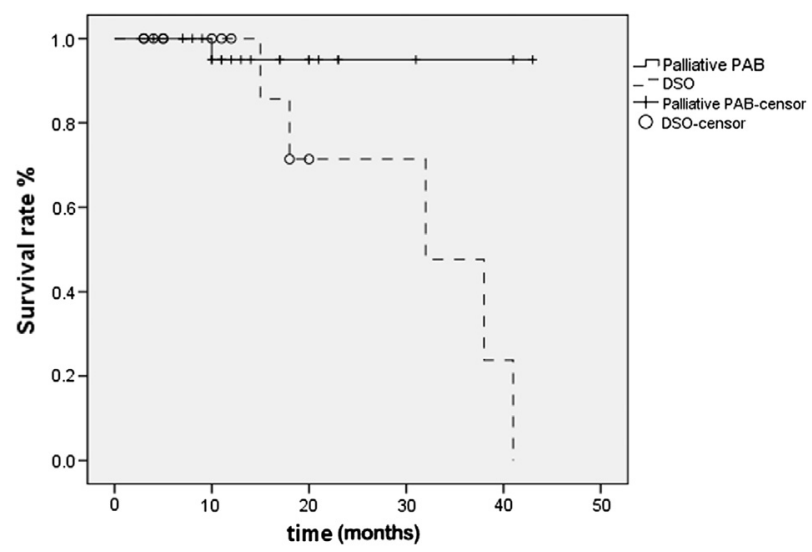

FIGURE 2. Kaplan-Meier curves for mortality. $P A B$, Pulmonary artery banding; $D S O$, double switch operation.

$\pm 0.04 ; P=.99)$. In the PAB group, 1 follow-up death was noted (recurrent pulmonary infection). The overall survival rate was higher in the PAB group $(66.7 \%$ in DS group vs $96.0 \%$ in $\mathrm{PAB}$ group; $P=.03$ ). The estimated survival rate from the time of operation was $100 \%$ at 1 year, $71.4 \%$ at 2 years, and $47.6 \%$ at 3 years in the DS group, whereas it was $96.0 \%$ at 1,2 , and 3 years in the PAB group (Figure 2).

The NYHA functional class I-II $(80.0 \%$ in the DS group vs $95.9 \%$ in the PAB group; $P=.02)$ and the mean systemic ventricular ejection fraction $(51.4 \% \pm 9.6 \%$ in the DS group vs $61.0 \% \pm 6.4 \%$ in the $\mathrm{PAB}$ group; $P=.01$ ) were higher in the PAB group. There was no significant difference $(P=.83)$ for the incidence of TR between the DS group and the PAB group. More information is available in Table 3.

At latest follow-up, significant aortic regurgitation and supraventricular tachyarrhythmia was identified in 3 and 1 patients in the DS group, respectively. No venous pathways, left ventricular outflow tract obstruction, or right ventricular outflow tract obstruction was noted. For patients who did not undergo the anatomic repair, the mean trans-banding

TABLE 3. Outcomes between groups

\begin{tabular}{lccr}
\hline \multicolumn{1}{c}{ Outcome } & $\begin{array}{c}\text { DS group } \\
(\mathbf{n}=\mathbf{1 0})\end{array}$ & $\begin{array}{c}\text { PAB group } \\
(\mathbf{n}=\mathbf{2 4})\end{array}$ & $\begin{array}{c}\boldsymbol{P} \\
\text { value }\end{array}$ \\
\hline $\begin{array}{l}\text { Tricuspid regurgitation } \\
\text { Mild }\end{array}$ & $4(40.0 \%)$ & $10(50.0 \%)$ & .83 \\
$\begin{array}{l}\text { Moderate } \\
\text { Severe }\end{array}$ & $2(20.0 \%)$ & $4(25.0 \%)$ & \\
$\begin{array}{l}\text { Systemic ventricular ejection } \\
\text { fraction }\end{array}$ & $51.4 \% \pm 9.6 \%$ & $61.0 \% \pm 6.4 \%$ & $<.01$ \\
$\begin{array}{l}\text { New York Heart Association } \\
\text { functional class I-II }\end{array}$ & $80.0 \%$ & $95.9 \%$ & .02 \\
Long-term survival rate & $66.7 \%$ & $96.0 \%$ & .03 \\
\hline
\end{tabular}

$D S$, Double switch; $P A B$, pulmonary artery banding. pressure gradient was $46.9 \pm 21.5 \mathrm{~mm} \mathrm{Hg}$ and the mean \pm standard deviation oxygen saturation was $95 \% \pm 3.1 \%$.

\section{DISCUSSION}

Long-term outcomes were compared between palliative PAB and anatomic correction in patients with ccTGA with deconditioned mLV using proper statistical methods. We found that the palliative PAB provided a lower mortality rate and indicated better cardiac function.

The long-term outcome of patients with ccTGA after conventional surgical approach is unsatisfactory. ${ }^{1-5}$ For patients in whom there is a coexisting ventricular septal defect or subpulmonary obstruction, many centers now follow a strategy that restores the $\mathrm{mLV}$ to the systemic position, either with a DS procedure or an atrial switch with a Rastelli reconstruction where necessary. Good results have emerged from many centers using this approach, and it represents a serious alternative to conventional repair. ${ }^{7-11}$

The patients in our study were in a more complex group. In the absence of an unrestrictive ventricular septal defect or subpulmonary obstruction, the mLV works against the lowresistance pulmonary vascular bed, whereas the mRV contends with high-resistance systemic circulation. Typically, the $\mathrm{mLV}$ has a reduced ventricular volume and wall thickness and may be squashed by the volume-loaded mRV. ${ }^{12} \mathrm{~Pa}-$ tients with deconditioning of the mLV need to be identified and considered for training to sustain the systemic pressure by means of PAB.

$\mathrm{PAB}$ has been demonstrated to train the left ventricle effectively, so all patients in our cohort were referred for PAB with an intention to move subsequently to anatomic repair. In all patients, the gradient over the banding increased to $53.2 \pm 11.1 \mathrm{~mm} \mathrm{Hg}$, whereas the mLV:mRV systolic pressure ratio increased from $0.31 \pm 0.15$ to 0.63 \pm 0.16 immediately after banding. Twenty-five patients' mLV $(62.5 \%)$ were judged to be well retrained and 15 patients $(37.5 \%)$ underwent the anatomic repair. These results are consistent with the results found by Winlaw and colleagues. ${ }^{13}$ Lacour-Gayet and colleagues ${ }^{14}$ pointed out some cellular changes and molecular alterations that resulted from stimulation of the left ventricle.

Clinicians are frequently impressed that patients with ccTGA and pulmonary outflow obstruction fare better than those without. It has unequivocally been established that PAB has several beneficial effects in patients with mRVs acting as the systemic ventricle, such as improved RV function, stabilized TR, and delayed cardiac transplantation. In addition, PAB may even be used as palliation. ${ }^{15,16}$ In our cohort, the morphologic $\mathrm{TR}$ and $\mathrm{mRV}$ ejection fraction improved significantly after PAB. Theoretically, PAB increases the afterload of the mLV and effects a shift of the interventricular septum back toward the midline position, inducing the $\mathrm{mRV}$ to become less spherical. This 
left ventricle interference moves the attachment of the septal leaflet of the tricuspid valve and improves tricuspid valve coaptation, thereby reducing regurgitation. As a result, right ventricle preload is reduced with improvement of right ventricle dilation and systolic function. ${ }^{15}$

For 25 patients who did not undergo anatomic repair, the survival rate, systemic ventricular function, TR, and NYHA functional class were satisfactory at latest follow-up. The only late death was caused by pneumonia without cardiac reasons. The relatively good trans-banding pressure gradient and oxygen saturation could indicate that the banding was not too tight and required no loosening. These encouraging results suggest that PAB may be left in place as long-term palliative treatment, which is consistent with the study by Cools and colleagues. ${ }^{17}$ Although there was an important concern about long-term functional capacity and exercise tolerance, NYHA functional class was better in palliative PAB patients at follow-up.

The fate of the retrained left ventricle after DS procedure for ccTGA remains a refractory problem. The group from Birmingham reported deterioration in $\mathrm{mLV}$ function in the trained group of patients after anatomic repair. ${ }^{6}$ In our cohort, late mortality, systemic ventricular function, and NYHA functional class were significantly deteriorated in the anatomic repair group compared with the palliative PAB group. In addition, the majority of late deaths $(80 \%$; 3 as a result of low cardiac output and 1 sudden death) in the anatomic group were in relation to poor cardiac performance. As some research has suggested, PAB may cause myocardial necrosis, fibrosis, and reduced ventricular work index. ${ }^{18}$ Imposition of a pressure overload induces both myocyte hyperplasia and hypertrophy rapidly, but the angiogenesis increases slowly and deficiently, which causes subendocardial ischemia. The placement of a looser band with lower initial left ventricle:right ventricle ratio (in the order of 50\%) may be a clinical alternative and provide better postanatomic repair mLV performance. However, Sharma and colleagues ${ }^{19}$ concluded that less-aggressive banding techniques are associated with decreases in $\mathrm{mLV}$ function after DS procedure. Outcomes of these techniques remain controversial and further investigation is required.

The time and degree of PAB may directly influence outcomes after anatomic repair. In our study, the baseline data about these factors showed no difference between the 2 groups.

Myers and colleagues ${ }^{20}$ recently reported their experience with the use of PAB in retraining the left ventricle in ccTGA. Late left ventricle dysfunction was significantly more frequent in older patients, both at PAB and at anatomic repair, with cut-off values of age 2 and 3 years, respectively. Within weeks after birth, a myocyte can no longer undergo mitosis, resulting in a fixed number of myocytes. ${ }^{18}$ When a child becomes older, his or her heart can hypertrophy in response to physiologic challenges, but may do so in an ultimately maladaptive fashion. In our study population, age at PAB was a risk factor for late deaths $(P=.01)$ and left ventricle dysfunction $(P=.03)$ after DS. Early PAB during infant periods may avoid long-term events, but our clinical data was too limited to evaluate this.

There is a trend that pre-DS mLV:mRV pressure ratio in the 3 deaths caused by mLV dysfunction was lower than survivors $(0.77 \pm 0.01$ vs $0.82 \pm 0.04 ; P=.09)$. However, the pre-DS mLV:mRV pressure ratio, as a continuous value, was not a risk factor for late death and left ventricle dysfunction after DS procedure in univariate analysis. The small sample size might be the reason. As a result, we cannot offer any guidance as to the suitable subgroup in whom the DS procedure should be pursued regarding $\mathrm{mLV}$ performance. We believe there might be an intrinsic correlation between $\mathrm{mLV}$ performance and late outcomes. Further multicenter study must be undertaken.

Some studies ${ }^{21}$ have recently identified PAB before DS operation as a risk factor for the development of aortic root dilation and aortic regurgitation after DS. Neoaortic regurgitation has been recently reported as a factor contributing to late left ventricle dysfunction in patients undergoing DS procedure. ${ }^{22,23}$ In our study, 3 patients $(30 \%)$ after DS repair had significant aortic insufficiency, and their $\mathrm{mLV}$ ejection fraction was $52 \%, 49 \%$, and $55 \%$ at follow-up, respectively. But no correlation could be established between aortic insufficiency and $\mathrm{mLV}$ dysfunction due to the very small sample size.

\section{Limitations}

Limitations of our study include its single-institution and retrospective nature, and the sample size is relatively small. Magnetic resonance imaging-based techniques, which may provide a better assessment of left ventricle mass, was unavailable. Optimal timing and degree of PAB remain perplexing, so all patients were managed individually and not according to a favorable treatment protocol. However, the baseline data between the 2 study groups were not different. Objective assessments of functional capacity (eg, cardiopulmonary exercise testing) are needed in future studies.

\section{CONCLUSIONS}

In ccTGA patients with regressed $\mathrm{mLV}, \mathrm{PAB}$ may be an ideal procedure because it allows LV training in those undergoing anatomic repair while improving or stabilizing right ventricle function and TR in others. Compared with PAB followed by DS operation, prolonged palliative PAB provides a lower mortality rate and indicates better cardiac function. The timing of PAB must be carefully considered. Further follow-up is warranted with a focus on exercise tolerance. 
The authors thank their colleagues, the perfusionists, the nurses, and others involved in the care of these babies. The authors also thank Dr Qiuming Chen for providing assistance regarding language editing.

\section{References}

1. Viktor H, Brian WD, John EM Jr, Freed M, del Nido PJ, Jonas RA. Longterm outcome of surgically treated patients with corrected transposition of the great arteries. J Thorac Cardiovasc Surg. 2005;129:182-91.

2. Mavroudis C, Backer CL. Physiologic versus anatomic repair of congenitally corrected transposition of the great arteries. Semin Thorac Cardiovasc Surg Pediatr Card Surg Annu. 2003;6:16-26.

3. Abdullah AA, Brian WM, Van Arsdell GS. Physiologic vs anatomic repair of congenitally corrected transposition of the great arteries: meta-analysis of individual patient data. Ann Thorac Surg. 2006;81:1529-35.

4. Mongeon FP, Connolly HM, Dearani JA, Li Z, Warnes CA. Congenitally corrected transposition of the great arteries ventricular function at the time of systemic atrioventricular valve replacement predicts long-term ventricular function. J Am Coll Cardiol. 2011;57:2008-17.

5. Dobson R, Danton M, Nicola W, Hamish W. The natural and unnatural history of the systemic right ventricle in adult survivors. J Thorac Cardiovasc Surg. 2013; 145:1493-501.

6. Brawn WJ, Barron DJ, Jones TJ, Quinn DW. The fate of the retrained left ventricle after double switch procedure for congenitally corrected transposition of the great arteries. Semin Thorac Cardiovasc Surg Pediatr Card Surg Annu. 2008; 11:69-73.

7. Langley SM, Winlaw DS, Stumper O, Dhillon R, De Giovanni JV, Wright JG, et al. Midterm results after restoration of the morphologically left ventricle to the systemic circulation in patients with congenitally corrected transposition of the great arteries. J Thorac Cardiovasc Surg. 2003;125:1229-41.

8. Devaney EJ, Charpie JR, Ohye RG, Bove EL. Combined arterial switch and Senning operation for congenitally corrected transposition of the great arteries: patient selection and intermediate results. J Thorac Cardiovasc Surg. 2003;125:500-7.

9. Murtuza B, Barron DJ, Stumper O, Stickley J, Eaton D, Jones TJ, et al. Anatomic repair for congenitally corrected transposition of the great arteries: a singleinstitution 19-year experience. J Thorac Cardiovasc Surg. 2011;142:1348-57.

10. Shin'oka T, Kurosawa H, Imai Y, Aoki M, Ishiyama M, Sakamoto T, et al. Outcomes of definitive surgical repair for congenitally corrected transposition of the great arteries or double outlet right ventricle with discordant atrioventricular connections: risk analyses in 189 patients. J Thorac Cardiovasc Surg. 2007;133: 1318-28.
11. Devaney EJ, Ohye RG, Bove EL. Technical aspects of the combined arteria switch and Senning operation for congenitally corrected transposition of the great arteries. Semin Thorac Cardiovasc Surg Pediatr Card Surg Annu. 2003;6:9-15.

12. Hornung TS, Calder L. Congenitally corrected transposition of the great arteries. Heart. 2010;96:1154-61.

13. Winlaw DS, McGuirk SP, Balmer C, Langley SM, Griselli M, Stümper O, et al Intention-to-treat analysis of pulmonary artery banding in conditions with a morphological right ventricle in the systemic circulation with a view to anatomic biventricular repair. Circulation. 2005;111:405-11.

14. Lacour-Gayet F, Piot D, Zoghbi J, Serraf A, Gruber P, Macé L, et al. Surgica management and indication of left ventricular retraining in arterial switch for transposition of the great arteries with intact ventricular septum. Eur J Cardiothorac Surg. 2001;20:824-9.

15. KralKollars CA, Gelehrter S, Bove EL, Ensing G. Effects of morphological left ventricular pressure on right ventricular geometry and tricuspid valve regurgitation in patients with congenitally corrected transposition of the great arteries. Am J Cardiol. 2010;105:735-9.

16. Poirier NC, Mee TBB. Left ventricular reconditioning and anatomical correction for systemic right ventricular dysfunction. Semin Thorac Cardiovasc Surg. 2000; 3:198-215.

17. Cools B, Brown SC, Louw J, Heying R, Meyns B, Gewillig M. Pulmonary artery banding as 'open end " palliation of systemic right ventricles: an interim analysis. Eur J Cardiothorac Surg. 2012;41:913-8.

18. Duncan BW, Mee RB, Mesia CI, Qureshi A, Rosenthal GL, Seshadri SG, et al Results of the double switch operation for congenitally corrected transposition of the great arteries. Eur J Cardiothorac Surg. 2003;24:11-20.

19. Sharma R, Bhan A, Juneja R, Kothari SS, Saxena A, Venugopal P. Double switch for congenitally corrected transposition of the great arteries. Eur J Cardiothorac Surg. 1999;15:276-81.

20. Myers PO, del Nido PJ, Geva T, Bautista-Hernandez V, Chen P, Mayer JE Jr, et al Impact of age and duration of banding on left ventricular preparation before anatomic repair for congenitally corrected transposition of the great arteries. Ann Thorac Surg. 2013;96:603-10.

21. Brawn WJ. The double switch for atrioventricular discordance. Semin Thorac Cardiovasc Surg Pediatr Card Surg Annu. 2005;8:51-6.

22. Bautista-Hernandez V, Marx GR, Gauvreau K, Mayer JE Jr, Cecchin F, del Nido PJ. Determinants of left ventricular dysfunction after anatomic repair of congenitally corrected transposition of the great arteries. Ann Thorac Surg. 2006;82:2059-65.

23. Bautista-Hernandez V, Myers PO, Cecchin F, Marx GR, Del Nido PJ. Late left ventricular dysfunction after anatomic repair of congenitally corrected transposition of the great arteries. J Thorac Cardiovasc Surg. Epub 2013 October 4. 